\title{
HOW MUCH DOES DISABILITY AFFECT THE LIKELIHOOD OF EMPLOYMENT
}

\author{
John Jensen \\ Sathi Sathiyandra \\ Mike Rochford \\ Davina Jones \\ Vasantha Krishnan \\ Keith McLeod
}

Centre for Social Research and Evaluation

Ministry of Social Development

\begin{abstract}
This paper describes the methodology and results of a study of the effects of disability on employment, and considers some of the policy implications of the findings. The study is based on data from two Statistics New Zealand surveys: the 2001 New Zealand Disability Survey and the 2001 Household Labour Force Survey. Key research questions include: what is the level of employment (both part time and full time) amongst people with disability; to what extent are people with disability less likely to be in employment when other personal characteristics (age, gender, ethnicity, qualifications, etc.) are taken into account; and how is the likelihood of employment related to type of disability. severity of disability and the existence of multiple types of impairment?
\end{abstract}

Multivariate analysis of disability data is used to produce a disability typology containing six categories: hearing. vision, mobility, co-ordination/dexterity, learning/memory, and psychological/psychiatric. Employment outcomes are examined for people with each of these types of disability, at different levels of severity. To develop the analysis beyond this descriptive level, a regression-based procedure is used to estimate for people with disability what their employment outcomes would have been in the absence of disability (assuming that other characteristics are unchanged). This provides a counterfactual to the descriptive results on employment, thus permitting assessment of the effect of each type of disability on employment. Additionally, an additive risk model is developed that relates the likelihood of employment to a general risk score based on the number of types of disability that a person has and the severity of those disabilities.

The results show that those with disabilities have a greatly diminished likelihood of full-time employment. However, the effect is much smaller when the outcome examined is any degree of employment (i.e. part-time or full-time employment). Those with a hearing disability experience a smaller negative effect in terms of employment outcomes than those with other types of disability, for whom the effects are approximately equal in size. The likelihood of employment diminishes sharply with the severity of disability for all of the disability types except hearing disability; for the latter type, employment does not seem to be very much affected by severity (to the extent that the severity of hearing disability is able to be assessed from the survey data).

The paper concludes by considering the study's implications concerning the effectiveness of policies for reducing the negative impact of disability on work participation. In the view of the authors, the findings suggest that there may be greater potential than has been appreciated to raise the level of full-time employment amongst people with disabilities. The challenge is to develop policies that would achieve this.

\section{Introduction}

Throughout the world, the number of people receiving ill health or disability related social assistance, as a proportion of the working-age population, has been increasing steadily. In many countries, these groups now constitute the majority of welfare recipients, with disability benefit costs being higher than unemployment benefit costs in 19 out of 20 OECD countries (OECD 2003).

The situation is no different in New Zealand, where significant growth has occurred over the past three decades in the number of people in receipt of ill health and disability related social assistance. In 1973, there were 8,000 people receiving a Sickness Benefit (SB) and 9000 people receiving an Invalids Benefit (IB). During the past 10 years, the number of people receiving SB has increased from approximately 29,000 in June 1993 to 40,000 in June 2003. The number receiving IB has almost doubled over this same 10-year period, from approximately 35,000 to 69,000 .

Indeed, the number of people with disabilities who are supported by the state may be even greater in New Zealand than SB/IB numbers suggest, due to the Accident 
Compensation Corporation (ACC) scheme. At 3 April 2004 , there were 15,583 claimants aged 16-64 years in receipt of weekly compensation of 26 weeks or more duration.' This scheme pays up to $80 \%$ of the wages of those who have accidents. This cohort of claimants may be viewed as a hidden disability population, given that the Statistics New Zealand definition of disability centres upon conditions that 'last six months or more and [are] not completely eliminated by an assistive device' (www.stats.govt.nz).

The study has been carried out to assist in implementation of the New Zealand Disability Strategy (Ministry of Social Development 2003:6), which is designed to remove barriers to social participation arising from disability.

This paper provides a condensed overview of the statistical procedures used in the analysis. A comprehensive account of the procedures (some of which are quite complex) is given in the fuller report 'Disability and Work Participation in New Zealand', which will be published on the Ministry of Social Development's website in 2004. That report also includes an analysis of the extent to which people with disabilities have an elevated likelihood of being in receipt of an incometested social security benefit.

\section{Variation in Labour Market Outcomes}

The starting point for the current analysis was the observed difference in labour market outcomes for those with disabilities, compared to those without. The difference is particularly pronounced in the case of fulltime employment outcomes, as shown in Table 1 below.

\section{Table 1: Comparative Labour Market Outcomes for the Disability and Non-Disability Populations Aged 18-64 Years}

\begin{tabular}{|l|c|c|}
\hline & $\begin{array}{c}\text { Disability } \\
\text { Population }\end{array}$ & $\begin{array}{c}\text { Non- } \\
\text { Disability } \\
\text { Population }\end{array}$ \\
\hline Any Employment & $58 \%$ & $77 \%$ \\
\hline $\begin{array}{l}\text { Full-time } \\
\text { Employment }\end{array}$ & $29 \%$ & $65 \%$ \\
\hline
\end{tabular}

This introduction concludes with a comment about language usage in the report. The central focus the analysis is on estimating the extent to which having a disability affects a person's likelihood of being in employment. The results are described in the report as estimating "the impact of disability on employment" (to cite one phrase used commonly).

Such phrases are not meant imply that a disabled person's reduced likelihood of employment is a simple consequence of the disability per se, with the corollary that any improvement would depend on eliminating or reducing the disability. In some cases it may indeed by possible to eliminate a disability (as occurs when vision is restored through cataract surgery) but in other cases the best prospect for improvement may be through better access to equipment, better support services, greater flexibility by employers, better understanding of the capabilities and potential of people with disabilities, elimination of prejudice and discrimination, greater selfconfidence and motivation by people with disabilities, and so on.

These comments point to there being a variety of mechanisms through which disability leads to lowered employment, and there is a substantial body of research on these mechanisms. Their common feature is that they all give rise to barriers to the employment of people with disabilities. To signal the importance of such barriers, consideration was given to using phrases such as "the impact of disability-related barriers to employment". However, repetition of such phrases could give an impression of wordiness, and also create a false expectation that the nature of the barriers would be examined in this report (a task that is beyond the scope of the present research).

In summary, a phrase such as "the impact of disability" should be seen as a convenient shorthand for "the impact of disability-related barriers to employment". Adoption of the former usage is not intended to direct attention away from the importance of labour market and societal factors that contribute to the outcome that is reported.

\section{Research Questions and Approach}

The analysis in this paper is both descriptive and explanatory, aiming to understand employment outcomes for people with disabilities and how better outcomes might be achieved. While the analysis aims to be explanatory, it is acknowledged that some of the relationships are complex, and some of this complexity may not be fully captured. The analysis has involved:

- undertaking a descriptive analysis of the relationship between disability and labour market outcomes

- fitting formal models of the relationship between disability and labour market outcomes

- profiling the different types of disability subpopulations and their differing labour market outcomes.

The study has several applications. Firstly, it will provide information that will facilitate the design of interventions to increase employment for those with disabilities. Secondly, it will analyse how the disability/employment relationship varies according to the type of disability. Interventions will therefore be able to be tailored to align them more closely with the needs of the different disability subpopulations, rather than adopting a 'onesize-fits-all' approach. Thirdly, the study will identify both disability-related and independent factors that may be inferred as influencing the relationship between disability and employment. This will enable us to better understand the factors that influence employment outcomes for this group. 
Key questions that the research seeks to answer are listed below.

- Are people with disabilities more disadvantaged in the labour market, when other individual characteristics are controlled for?

- What is the relationship between type of disability, severity of disability, and employment?

- What is the relationship between demographic variables (such as age, education and age of onset of disability) and labour market outcomes? For example, are those with an older age of onset of disability at less risk of poor outcomes than those for whom disability occurs at a younger age?

\section{Data Sources and Variables Used}

\section{Data Sources}

\section{The New Zealand Disability Survey 2001}

The Disability Survey was conducted by Statistics New Zealand, in conjunction with the 2001 Census, which included two questions on whether people had activity limitations. This information was then used to target a post-Census sample of approximately 40,000 people in 2001 to interview for the Disability Survey.

In recognition that the Census items would not succeed in identifying all people with disabilities, the sample was supplemented by a second Census sample of people who did not indicate activity limitations.

Although the majority of interviews were conducted by phone, where phone contact could not be made, the address was visited and a face-to-face interview was conducted. Where appropriate, someone other than the nominated respondent answered questions on their behalf (e.g. a family member). If requested, interpreters were arranged to translate questions, including into sign language.

The definition used for survey purposes was that "a disability is any self-perceived limitation in activity resulting from a long-term condition or health problem; lasting or expected to last six months or more and not completely eliminated by an assistive device' (www.stats.govt.nz). This is to say that the population captured by this survey may not necessarily define themselves as being 'disabled' but are identified by their data as such for survey purposes.

In practice, the definition of disability is having at least one of 25 specified impairments or limitations. The questions relating to these limitations started with the statement 'I am going to ask you some questions about long-term difficulties that some people have doing things' (with 'long-term' defined as lasting or expected to last six months or more). An example of difficulties is 'Can you get in and out of bed by yourself: easily, with difficulty or not at all? Is that because of a long-term condition or health problem?' Those who did not answer 'easily' to the first question or 'no' to the second question were categorised as having a disability. This part of the survey concluded with a general question that asked whether the respondent had any other conditions or health problems not previously mentioned that make it difficult or impossible 'for you to do everyday things that people your age can usually do'.

This approach to defining disability is similar to that used in Australia in the 1998 Survey of Disability, Ageing and Carers, although the list of screening questions differed.

The approach is compatible with the World Health Organisation definition of disability: 'any restriction or lack [resulting from an impairment] of ability to perform an activity in a manner or within the range considered normal for a human being'.

Because the present analysis is concerned with the effect of disability on employment, it uses data on only working-age people (defined for present purposes as those aged 18-64 years). The number of working-age people with disabilities used for the analysis is 3,367 .

\section{The Household Labour Force Survey}

This report compares the employment outcomes for the disability population with employment outcomes for people without disabilities. To do this, a data source on employment outcomes for the general population was used. The Household Labour Force Survey (HLFS), which is conducted annually, collects information on employment and a range of demographic variables including age, gender, ethnicity, qualifications and family type. Data on 21,298 HLFS respondents was used for the analysis.

\section{Variables Used}

\section{Variables Used to Measure Disability}

The Disability Survey contained an extensive range of questions that provide a large amount of detailed information about the respondents' disabilities. These questions include the ones about the 25 specified impairments, referred to earlier, and a number of supplementary questions. To analyse the effect of disability on employment using the intended analysis design, it was necessary for the many detailed aspects of disability included in the survey to be condensed into a compact set of disability types. With this purpose in mind, 31 variables were specified as potentially able to contribute to the specification of such a typology.

Some of these variables were tripartite, relating to whether the respondent was able to carry out a specified activity easily (scored a 0 ), with difficulty, because of a long-term condition (scored as 1), or not at all, because of a long-term condition (scored as 2). Others were binary (such as whether the person needed support from others because of an intellectual disability, scored as 0 for 'no' and 1 for 'yes').

Exploratory analysis of the properties of the 31 variables led to some being excluded as unsuitable for various 
reasons, resulting in a reduced set of 22 , which then was used to specify the typology. The 22 measurement items are set out in Section 4 below.

\section{Control Variables Used in Estimating Impact of Disability}

To be able to assess the likely impact of disability on employment, it was necessary to identify a set of demographic variables common to the both the Disability Survey and the HLFS that were appropriate in controlling for factors other than disability that are associated with employment. Exploratory analysis led to six control variables being selected: educational qualifications; age; gender; ethnicity; social marital status; and parenting status.

\section{Outcome Variables}

Examination of the information on employment in the Disability Survey and the HLFS led to the specification of two binary outcomes variables related to employment:

- whether the respondent had any level of employment (either part time or full time), specified as a binary dummy variable whose values correspond to 'yes' or 'no'

- whether the respondent was in full-time employment (defined for the purposes of the study as more than 30 hours per week).

A third binary outcome variable, relating to whether the respondent was in receipt of an income-tested social security benefit, was also specified. However, it is not further described here because the analysis carried out using that variable is not described in this paper.

\section{Specification of a Compact Set of Disability Types}

The task of examining the effect of disability on employment could not feasibly be undertaken by trying to determine the separate effect of each of the many specific limitations distinguished in the Disability Survey. The first stage of analysis thus involved seeking to develop a compact classification that could provide a useful basis for subsequent analysis of employment. Statistics New Zealand had already predefined some composite categories, such as 'agility disability' and 'sensory disability", but it was decided that a post-survey classification of the types of limitation experienced could provide more useful groupings for analytical purposes. It was decided to ascertain whether the data lent itself to the development of a statistically well-specified classification based upon a natural clustering of the limitation variables.

As noted in the previous section, 32 potential measurement items were specified and then reduced to a set of 22 on the basis of exploratory analysis that examined their suitability for a typology analysis.

The pattern of statistical association between the items was then examined, using - in the first instance-the
Pearson product moment correlation coefficient. The matrix of correlations is shown in Table 2, with values above 0.3 highlighted. The key to the items precedes the matrix.

Because the interview questions are in various forms, the measurement items (as indicated earlier) are a mix of tripartite and binary variables. Furthermore, they are found to have substantially differing distributions/base rates. The measurement items thus constitute an untidy set of variables for a conventional correlational analysis, and an issue arises as to the robustness of the Pearson coefficient to establish the pattern of associations. This issue was examined by generating and comparing matrices based on three other measures of statistical association, namely Fischer's Exact Test, Chi Square and Phi/Phi-Max. All of these measures showed essentially the same pattern of associations, indicating that the structure revealed was robust to the measure of association used.

The variables were initially grouped by inspection of the matrices for the different measures of association. This led to the conclusion that the items could be clustered either into six groups, with two of these showing a moderate degree of association, or into five groups, which was the clustering produced if the associated groups were combined into one.

As a second stage, the matrix of Pearson coefficients was factor analysed. The factor analysis gave a six factor solution, which matched the six group clustering identified by inspection. That clustering was adopted as the disability typology for use in subsequent analysis

On the basis of the clustering, respondent values on groups of items were combined to give scores on six composite disability variables. The clustering is shown in the following table.

In addition to those having one or more of the particular limitations included in the Disability Survey, there was a residual group of $9 \%$ of the respondents who had only an 'other' type of limitation, not otherwise specified. As those respondents could not be characterised by means of the six disability types, and there was no way of ascertaining the extent to which they had common characteristics, they were excluded from further analysis.

\section{Scoring the Disability Types for Severity}

The final stage of developing the typology was specifying a procedure for giving each respondent a score on each type of disability. A respondent's score on a disability type was obtained by adding together the respondent's values on the items making up the disability type. The score thus reflects the number and extent of the respondent's limitations of that type.

The score is interpreted as a measure of the degree of disability that the respondent has in the designated disability category, and is referred to as a severity score. A score of 0 indicates that the respondent does not have that type of disability. 


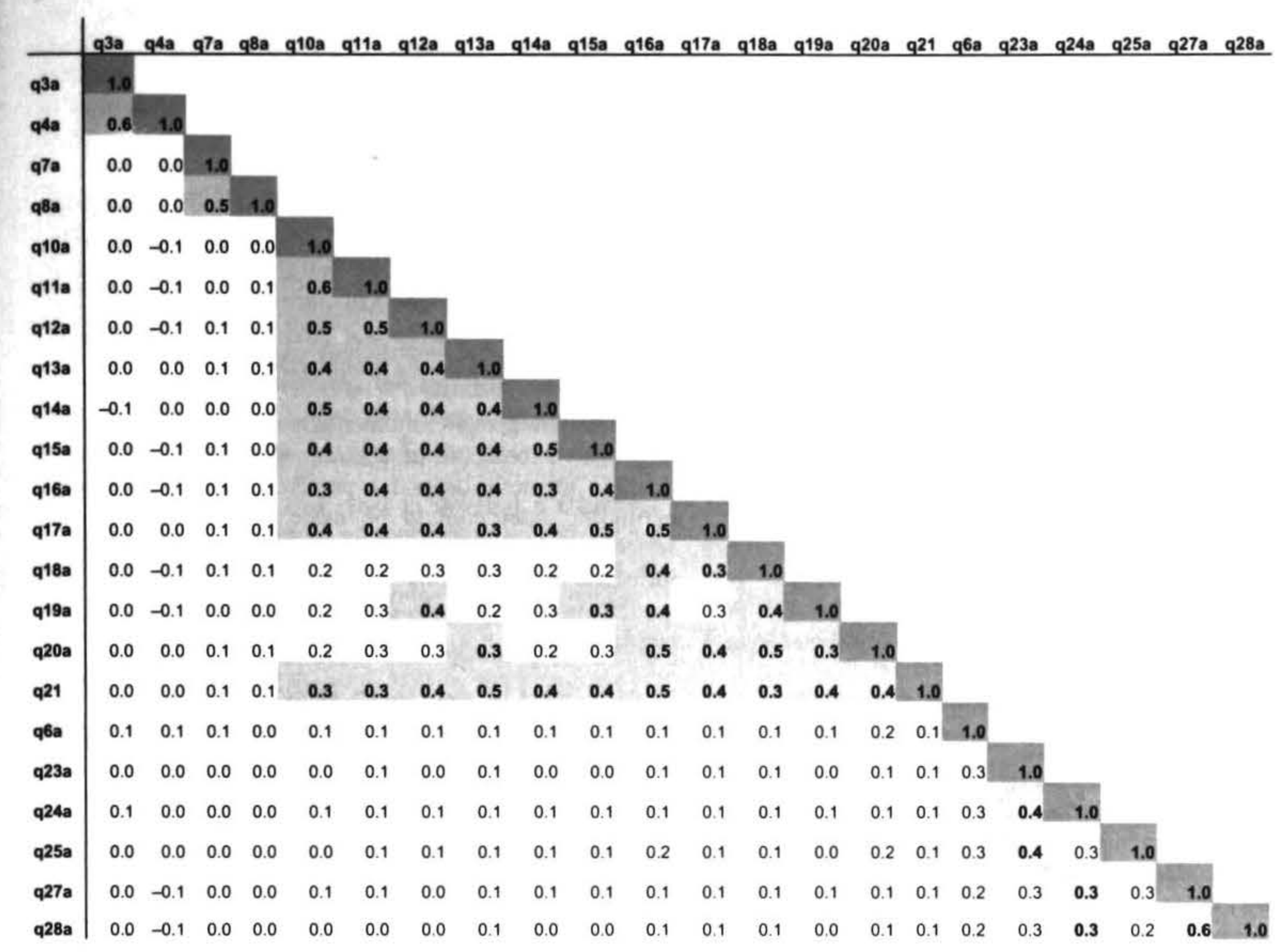

Key to Table 2 (question numbers refer directly to the Disability Survey questionnaire)

q10a-Walking 350 metres

q11a-Walking up and down stairs

q12a-Carrying 5 kilos while walking 10 metres

q13a-Moving between rooms

q14a-Standing for 20 minutes

q15a-Bending down and picking something up off the floor

q16a-Dressing and undressing yourself

q17a-Cutting your own toenails

q18a-Grasping or handling things like scissors or pliers

q19a-Reaching in any direction

q20a-Cutting own food

q21-Getting in and out of bed by yourself

\author{
q3a-Hearing a conversation with one person \\ q4a-Hearing a conversation with three people \\ q6a-Difficulty in speaking and being understood \\ q7a-Seeing newspaper print \\ q8a-Seeing a face across a room \\ q23a-Learning \\ q24a-Remembering \\ q25a-Needing support from others for intellectual disability \\ q27a-Difficulty doing normal age-specific activities \\ q28a-Difficulty communicating or socialising with others
}


Table 3: The Six Disability Types

\begin{tabular}{|l|l|}
\hline \multicolumn{1}{|c|}{ Type } & Measurement Items \\
\hline $\begin{array}{l}\text { Hearing Disability (partial } \\
\text { or total deafness) }\end{array}$ & Q3a, Q4a \\
\hline $\begin{array}{l}\text { Vision Disability (partial or } \\
\text { total blindness) }\end{array}$ & Q7a, Q8a \\
\hline $\begin{array}{l}\text { Restricted Mobility } \\
\text { (mobility and strength } \\
\text { limitations) }\end{array}$ & Q10a-Q15a \\
\hline $\begin{array}{l}\text { Restricted Co-ordination/ } \\
\text { Dexterity (dexterity and } \\
\text { agility limitations) }\end{array}$ & Q16a-Q20a, Q21 \\
\hline $\begin{array}{l}\text { Learning/Memory } \\
\text { Disability (learning and } \\
\text { memory problems, need for } \\
\text { support from others. } \\
\text { difficulty in speaking, } \\
\text { intellectual) }\end{array}$ & \\
\hline $\begin{array}{l}\text { Psychological/Psychiatric } \\
\text { Disability (long-term } \\
\text { emotional, psychiatric or } \\
\text { psychological condition, } \\
\text { difficulty with } \\
\text { communicating, socialising, } \\
\text { everyday things) }\end{array}$ & Q27a, Q28a \\
\hline
\end{tabular}

Inspection of the severity scores showed that results could conveniently be presented by means of five severity categories, corresponding to scores of $0,1,2,3$, and 4 or more. This standard format has been used for all disability types except for Psychological/Psychiatric Disabilities, which has a range of only 0 to 3 because the score is generated from only two items, both binary.

\section{Prevalence of These Six Types of Disability}

As shown in Table 4 below, physical disabilities were the most common types of disabilities experienced, with $50 \%$ of respondents indicating that they had restricted mobility and $30 \%$ having restricted co-ordination/dexterity. The least common type of disability was vision disability at just $9 \%$. The categories are not mutually exclusive and therefore do not add up to $100 \%$, as some people have disabilities of more than one type.

Table 4: Prevalence of Different Disability Types amongst the Disability Population Aged 18-64 Years

\begin{tabular}{|l|c|}
\hline Type of Disability* & Percentage \\
\hline Vision Disability & $9 \%$ \\
\hline Hearing Disability & $29 \%$ \\
\hline Restricted Mobility & $50 \%$ \\
\hline Restricted Co-ordination/Dexterity & $30 \%$ \\
\hline Learning/Memory Disability & $23 \%$ \\
\hline Psychological/Psychiatric Disability & $20 \%$ \\
\hline Other Disability** & $25 \%$ \\
\hline
\end{tabular}

* People can be in more than one disability group and therefore the categories are not mutually exclusive. ** As previously stated, the analysis excludes respondents whose only disability was in the 'other' category. The $25 \%$ appearing in the 'other' category of the table are respondents who had some other disability in addition to one or more of the specified types.

\section{Assessing the Impact of Disability on Employment}

\section{Obtaining Counterfactuals}

To assess the impact of disability, it is necessary to be able to estimate for various groups of people with disabilities the outcomes that would be expected to have occurred if they had not had disabilities (but were the same in other respects). An estimate of this type is commonly referred to as a 'counterfactual'.

By comparing the counterfactual with the actual employment outcome of a group with disabilities, it is possible to move beyond a purely descriptive analysis, permitting inferences to be made about the extent to which the observed outcome is partly a reflection of the influence of disability on employment (acting in combination with non-disability factors that affect employment).

In the context of the present study, being the same 'in other respects' means being the same in terms of the relevant demographic factors that had been included in the Disability Survey and the HLFS. Some of these characteristics may themselves be the consequence of disability (e.g. low qualifications) and the impact of disability could be understated as a consequence. A caveat also needs to be made about the possible effect of 'omitted variables'. The variables available for estimating the counterfactual are limited to demographic variables included in both the Disability Survey and the HLFS. Those common demographics make up only some of factors likely to be influencing employment. As a result, the 'control' variables available for estimating the counterfactual do not constitute a comprehensive set. This may reduce the accuracy of the counterfactual estimates.

To develop a procedure for estimating counterfactuals, it was necessary to determine which of the common demographic variables affect employment outcomes amongst people without disability. This would have been straightforward if the HLFS included questions on disability, but unfortunately it does not. The relationship between the demographic variables and disability was therefore analysed using the whole of the HLFS sample. This procedure took its rationale from a prior estimate that $17 \%$ of the sample could be expected to be without disability, so that the non-disabled part of the sample could be expected to dominate the results of the analysis, which thus would give a reliable identification of the variables affecting employment amongst non-disabled people. The variables identified were: age; ethnicity; educational qualifications; gender; whether the person had a partner; and whether the person had children. (The last three variables were found to influence the outcomes not only through simple 'main' effects but also through interactions that resulted in combined effects that were not simply the sum of their separate effects.) These six variables are referred to as the control variables. 
Further analysis was undertaken to determine how these variables could be specified in the most economic way that preserved the major part of their statistical associations with employment. Thus, for example, qualifications were expressed as a binary dummy variable of 'post-school qualification(s)' versus 'no post-school qualification'.

The datasets for both the Disability Survey and the HLFS were then used to create a synthetic dataset of unit-record data for respondents distinguished according to whether or not they had a disability. The variables in the synthetic dataset (apart from presence of a disability) were employment and the six demographic control variables. The procedure for generating the synthetic dataset was complicated and is not further described here. It is set out in Jensen et al (2004).

The synthetic dataset was used to develop a statistical estimation procedure, based on specifying and fitting a set of regression models, for calculating the likelihood of employment if no disability, given the control variables.

The regression equations provided a means of estimating for any person in the Disability Survey the likelihood of their being in (any) employment, and of being in full-time employment, given their values on the control variables. For any group of people in the Disability Survey (e.g. people with a vision disability at severity level 1), a counterfactual could be obtained with respect to employment (any employment or full-time employment), by estimating the likelihood of employment for each person in the group and calculating the average for the group. This average is the proportion of the group that could be expected to be in employment in the absence of disability.

\section{Impact Assessment}

\section{Assessment of the Impact of Disability}

An analysis (paralleling that carried out on the HLFS sample) was made of the association between demographic characteristics and employment outcomes amongst people with disability. The characteristics identified as being associated with employment were (unsurprisingly) the same six found in the earlier HLFS analysis.

An examination was then made of aspects of disability that affect the employment outcomes of people with disability, controlling for the demographic factors. This was done using logistic regression. It was found that employment (whether measured as any employment or full-time employment) is affected by the disabled person's type of disability and severity of disability.

This result, together with the procedure of estimating counterfactuals, laid the basis for analysing the impact of disability, whether considered simply in terms of the presence or absence of disability or in relation to the type and severity of disability.
Estimates are given below for the impact of disability on being in any degree of employment and being in full-time employment. The impact of a particular type of disability at a designated level of severity is specified as the proportion of people in the category who have a specified outcome (e.g. any employment) divided by the counterfactual proportion (e.g. the proportion of those people who would have been in any employment in the absence of disability).

For example, if the proportion in employment is $20 \%$, and the counterfactual indicates that $80 \%$ of those people would be expected to be in employment in the absence of disability, the impact would be given as $20 / 80$ or 0.25 . Where there is no impact, the impact figure will be 1 . The larger the impact, the further the figure will be from 1. An impact of 0.25 indicates that the proportion in employment is only a quarter what it would have been in the absence of disability, which might be regarded as a large negative impact.

\section{Impact Analysis: The Effect of Disability on Employment}

This section describes the first phase of the analysis to assess the impact of disability upon employment outcomes. The following section will sharpen this focus by incorporating into the analysis information on both number and severity of disabilities.

\section{Impact on Labour Market Outcomes for Population as a Whole}

As shown in Table 5 below, for the total disability population, the presence of a disability means that the percentage employed is about four-fifths of the value expected in the absence of disability. In other words, disability has reduced employment by a fifth. When fulltime employment is examined, the impact is far more pronounced. In this case, the presence of a disability reduces employment probability to a little less than half of what it would have been.

Table 5: The Impact of Disability on Labour Market Outcomes

\begin{tabular}{|l|c|c|}
\hline & Employed & $\begin{array}{c}\text { Full-Time } \\
\text { Employed }\end{array}$ \\
\hline Actual & $59 \%$ & $29 \%$ \\
\hline If No Disability & $72 \%$ & $63 \%$ \\
\hline Impact of Disability & 0.82 & 0.46 \\
\hline
\end{tabular}

\section{Impacts by Disability Type}

When the results for any type of employment are examined across disability subpopulations (Table 6 below), the impact ratios range from 0.62 to 0.69 with the exception of hearing disability, for which the value is 0.87 (indicating a relatively small impact). For full-time employment, the impact ratios (not including hearing) range from 0.29 to 0.35 , with the ratio for hearing being 0.45 . These results confirm the earlier finding (Table 2) that employment outcomes have a weaker association 
with hearing limitations than with other types of disability.

Table 6: The Impact of Disability Type on Labour Market Outcomes

\begin{tabular}{|l|l|l|}
\hline Disability Type & Employed & $\begin{array}{l}\text { Full-Time } \\
\text { Employed }\end{array}$ \\
\hline Vision Disability & 0.62 & 0.34 \\
\hline Hearing Disability & 0.87 & 0.45 \\
\hline Restricted Mobility & 0.68 & 0.35 \\
\hline $\begin{array}{l}\text { Restricted Co-ordination/ } \\
\text { Dexterity }\end{array}$ & 0.63 & 0.30 \\
\hline $\begin{array}{l}\text { Learning/Memory } \\
\text { Disability }\end{array}$ & 0.69 & 0.34 \\
\hline $\begin{array}{l}\text { Psychological/Psychiatric } \\
\text { Disability }\end{array}$ & 0.63 & 0.29 \\
\hline
\end{tabular}

\section{Impacts for Different Demographic Groups}

If the results for any type of employment are broken down by demographic subcategory, some interesting findings emerge, especially in relation to the situation of older people with disabilities. The impact ratio of those with disabilities in the 50-64 age group is 0.74 . This compares with ratios of 0.88 and 0.86 for those aged 18 24 and $25-49$ respectively.

The levels of employment of people in the Pacific and 'other' ethnicity categories were significantly more affected by disability than the levels of those with European and Māori ethnicity. The former groups had impact ratios of 0.70 and 0.61 respectively, compared to ratios of 0.82 and 0.85 for Europeans and Mãori. In addition, there was a relatively large impact of disability on those without qualifications. For that group the ratio was 0.71 , compared with 0.90 and 0.88 for those with school qualifications and post-school qualifications, respectively.

The impact of disability on the prospects of people who were partnered and had children was quite small (0.95). For people in other types of families there was a larger impact (with ratios ranging from 0.73 to 0.76 . The reason for this pattern is not entirely clear-other characteristics, including the severity of disability, could be mediating this outcome. Possible reasons could include social pressure to work, for adults in families, 'normalisation' effects of family membership or the impact of "workrelated' Family Assistance. However, further research would be required to determine whether any of these factors is significant. In relation to the causes of disability, the strongest impact arose from disease or illness. For this group the impact ratio was 0.69 compared with ratios ranging from 0.83 to 0.87 for the other causation groups
Age of onset of earliest disability also shows variation in employment outcomes. For example, the younger age of onset ( $0-14$ years) and older age of onset (45-64 years) both had considerably reduced probability of employment. Information on the duration of disability also suggests that the probability of employment is lower for those with long durations (20+ years).

\section{Joint Impact of Disability Type and Severity on Employment (Any Level)}

Within each disability subpopulation, people experience differing levels of limitation. For the vision, hearing, restricted mobility and restricted co-ordination/dexterity disabilities, each screening question therefore incorporated three possible responses-the respondent could do the action easily, with difficulty or not at all. Scores of 0,1 and 2 were assigned to these responses respectively, and scores were added together where a respondent experienced more than one limitation. In this manner, both the number and severity of limitations experienced were incorporated into scores.

Figures 3 to 8 show, for each disability type, the proportion in employment at each level of severity. These proportions are shown by the bars. The figures also show (by means of dotted lines) the likelihood of any employment in the absence of a disability. The process used to derive these likelihoods has been discussed earlier. The gap between these lines and the top of each bar represents the impact of disability on employment outcomes for that subgroup.

As shown in Figures 1, 2 and 3, vision disabilities, restricted mobility and restricted co-ordination/dexterity, all display a consistently negative relationship with employment prospects. That is to say that the higher one's score within any of these subgroups, the higher one's likelihood of being unemployed. While the graph is a little uneven for the two physical disabilities, a generally negative trend is apparent.

As shown in Figure 4, the hearing group was the only disability variable that did not demonstrate a consistent relationship with employment outcomes. Total employment varied from $54 \%$ to $66 \%$ for all score levels, which was consistently higher than for other subpopulations. For those with the highest score of 4 points on the severity gradient, full-time employment was still markedly higher than for those with lower severity scores, at $51 \%$. These results are also consistent with earlier correlation and descriptive results.

For the learning/memory and psychological/psychiatric disability groups, questions were binary with only yes/no answers, which were assigned scores of 1 and 0 respectively. Therefore, for these subpopulations, the number of limitations is incorporated into the score, but a measure of severity is not. The risk levels experienced by these two groups are illustrated in Figures 5 and 6 below. 
Figure 1: Employment Outcome for Those with Vision Disabilities

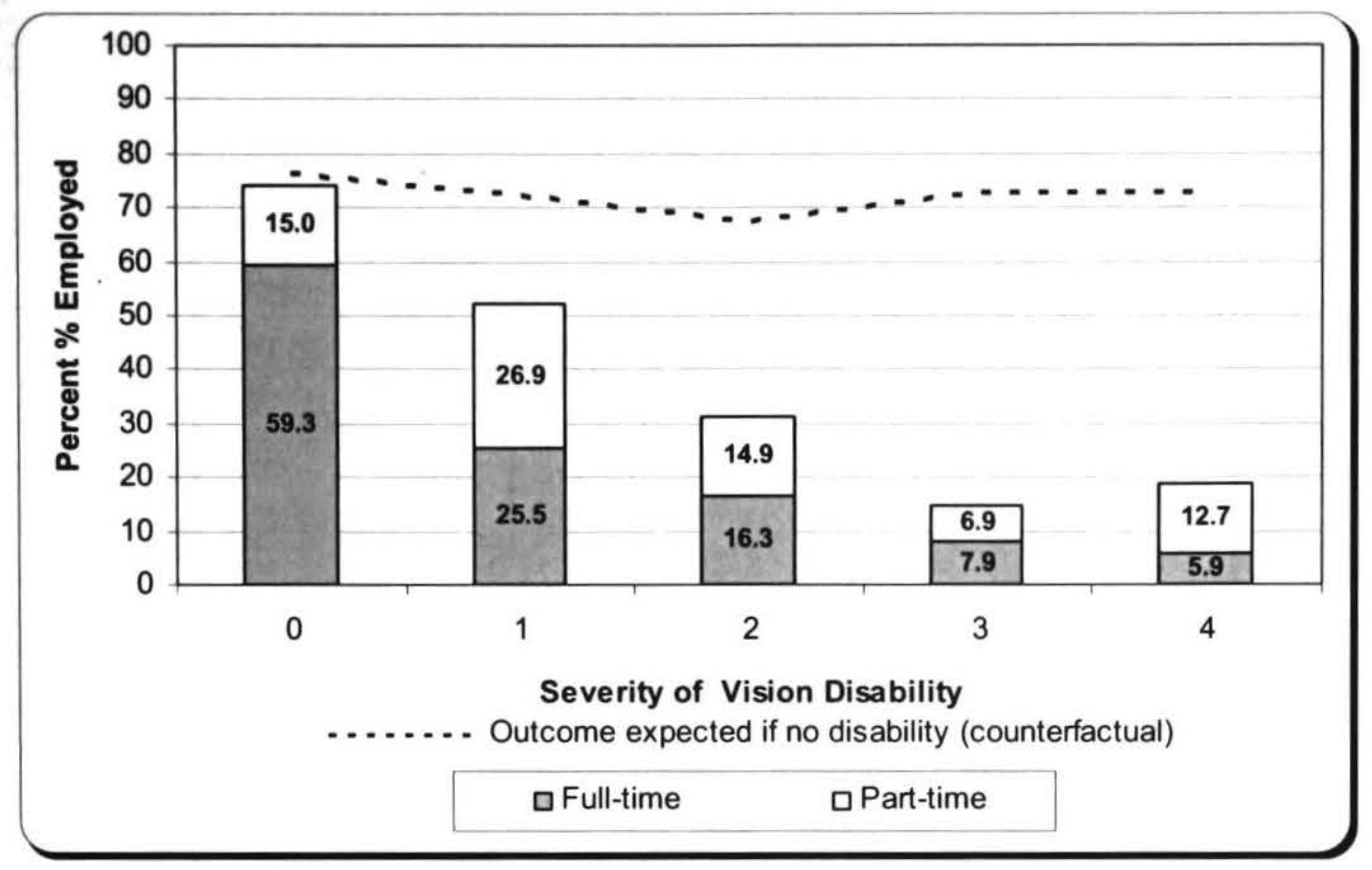

Figure 2: Employment Outcome for Those with Restricted Mobility

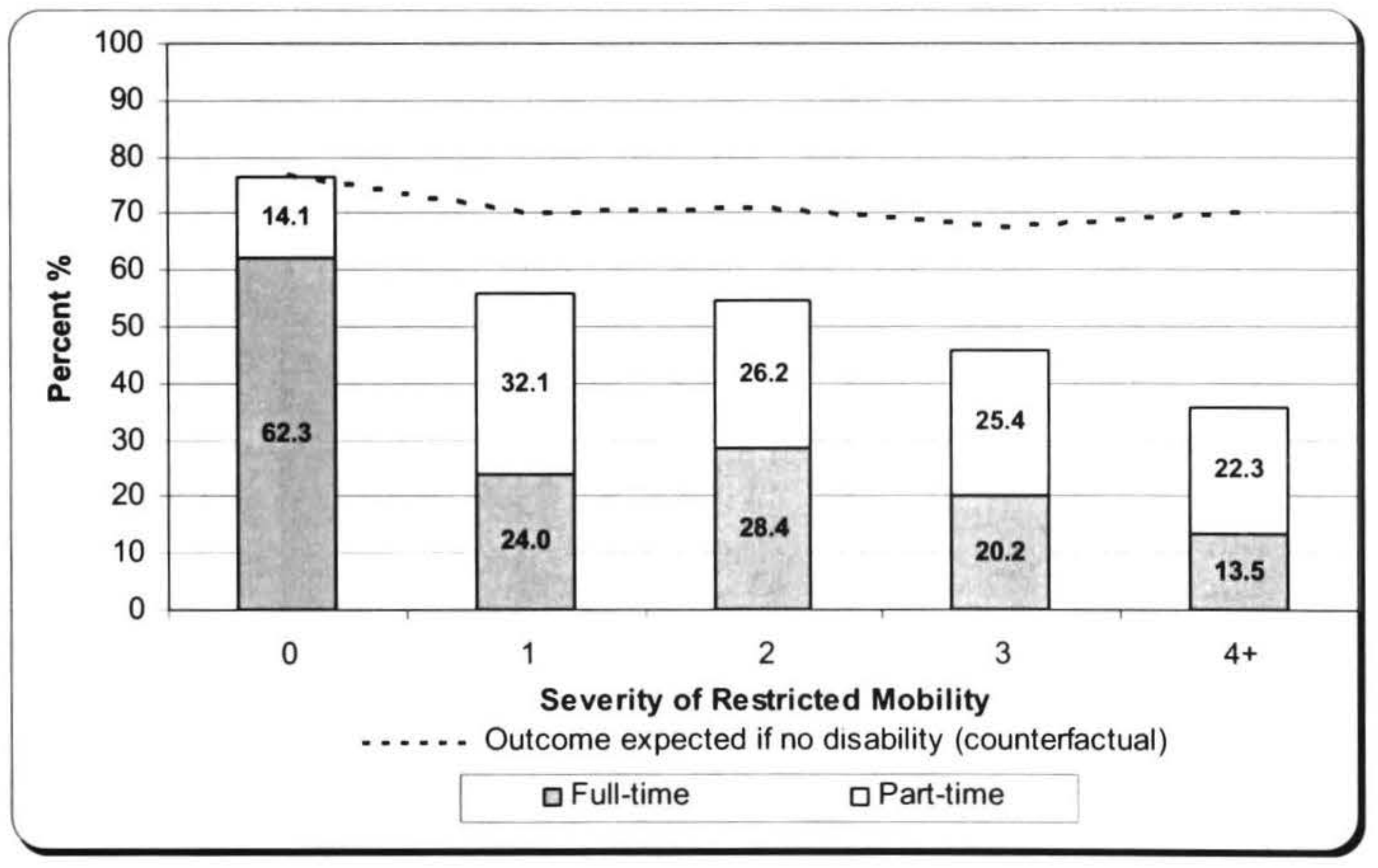


Figure 3: Employment Outcome for Those with Restricted Co-ordination/Dexterity

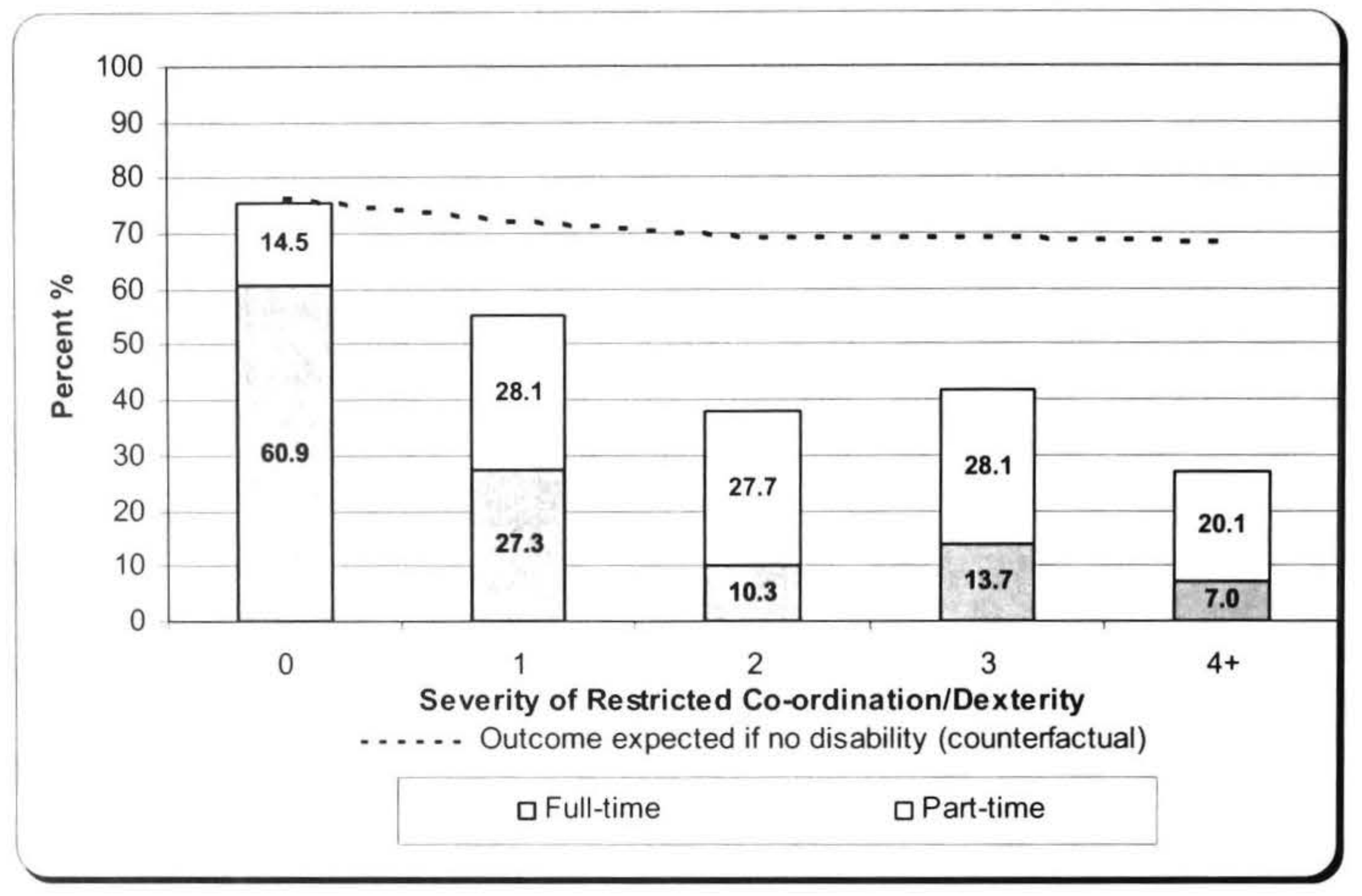

Figure 4: Employment Outcome for Those with Hearing Disabilities

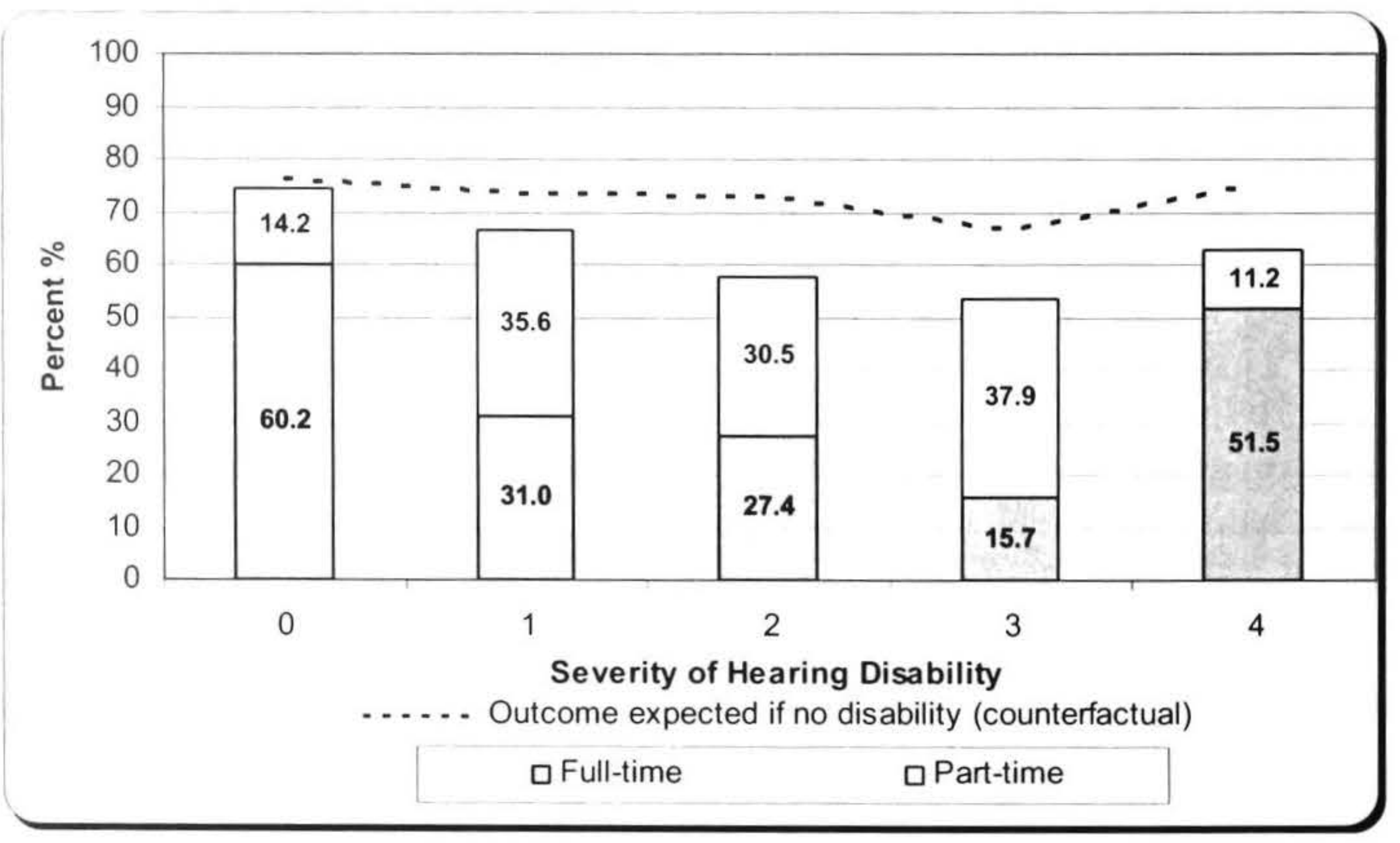


Figure 5: Employment Outcome for Those with Learning/Memory Disabilities

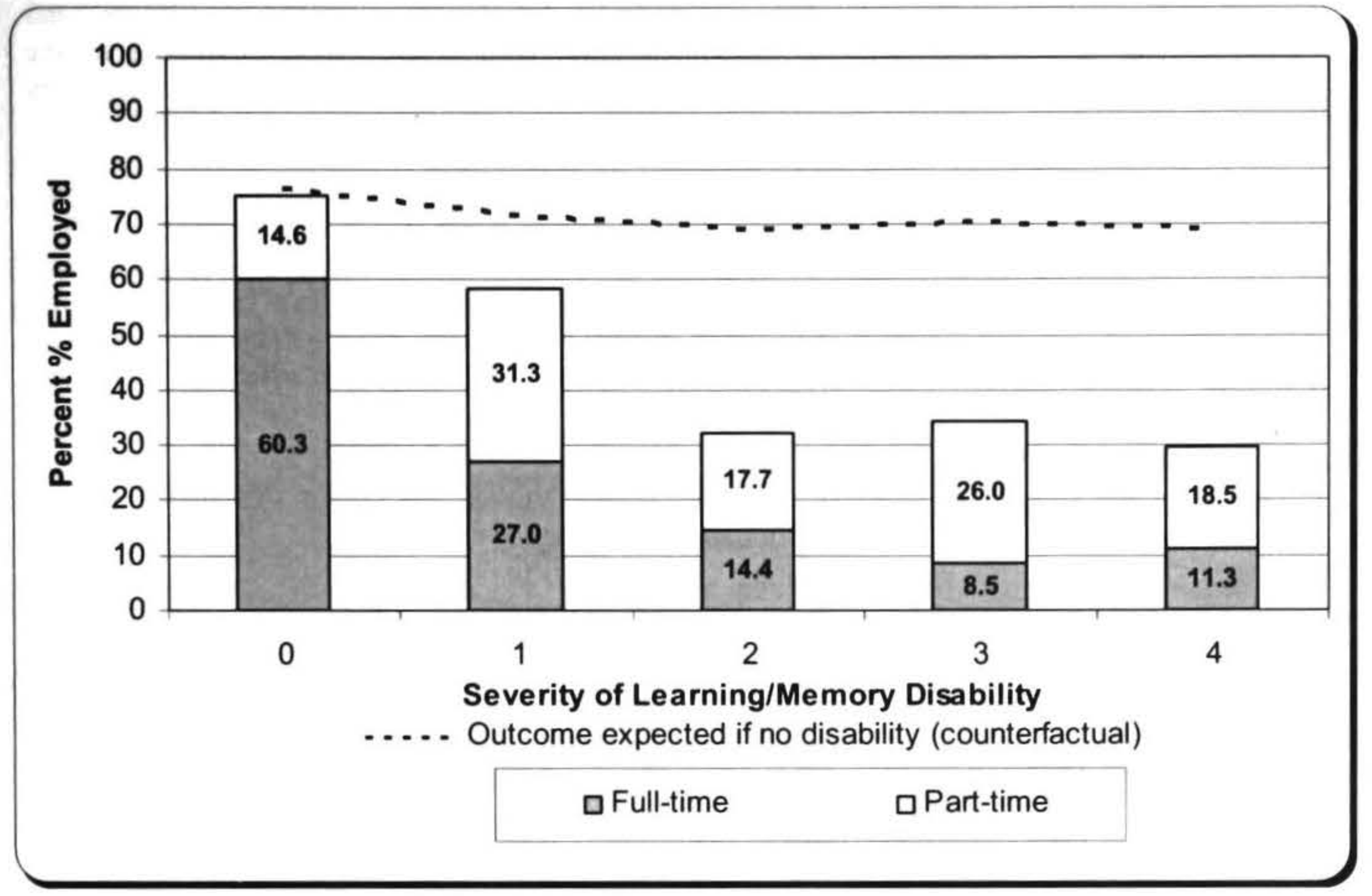

Figure 6: Employment Outcome for Those with Psychological/Psychiatric Disabilities

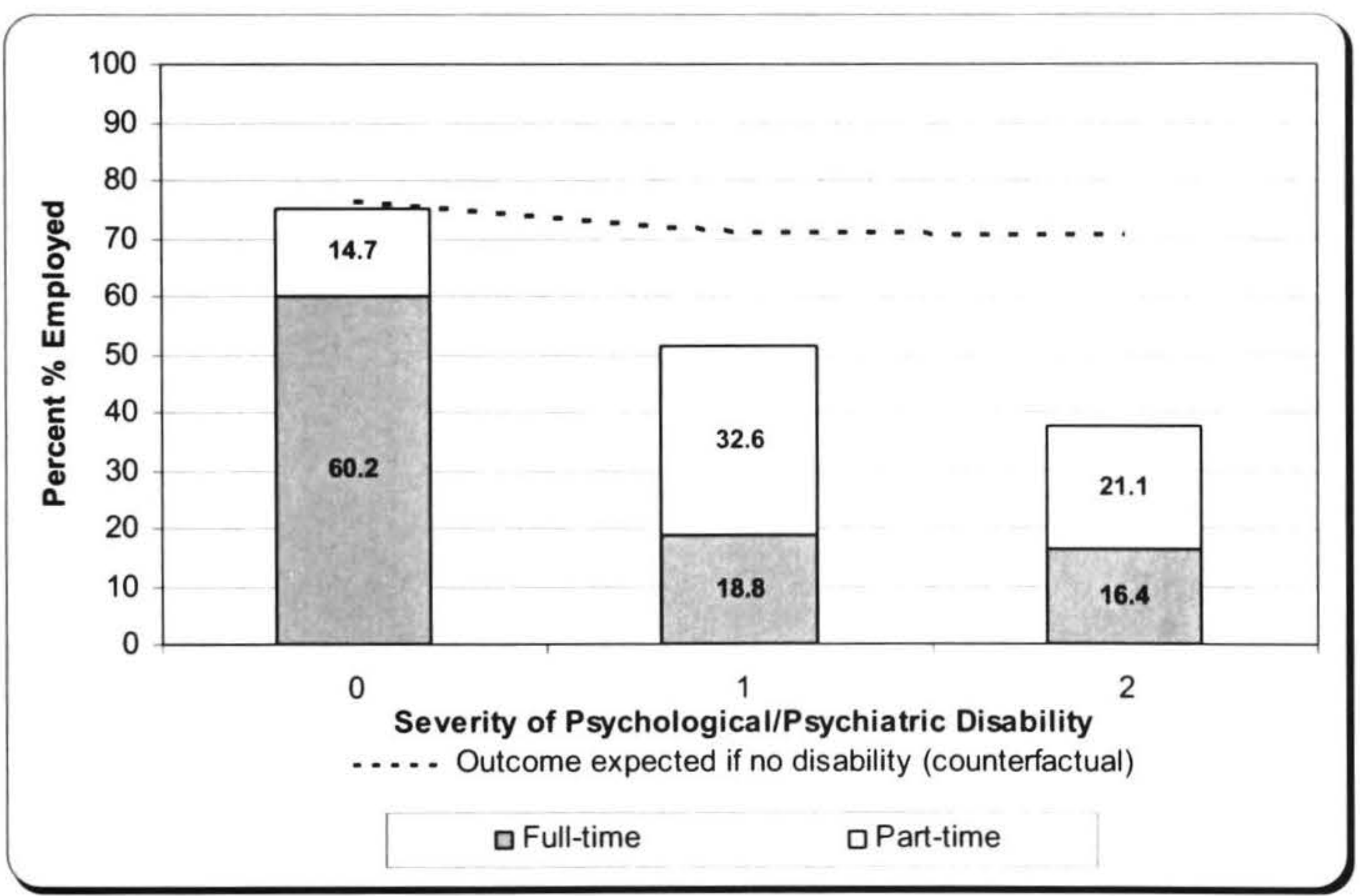


Summary: Impact Analysis-Any Level of Employment

The following table shows the ratio of the actual employment outcomes to the counterfactual proportions for employment of people with various disabilities, at various levels of severity. This analysis is represented in Figures 3-8, and is summarised in Table 7.

Table 7: Joint Impact of Disability Type and Severity on Employment (Any Level) for Those Aged 18-64 Years

\begin{tabular}{|l|l|l|l|l|l|}
\hline \multirow{2}{*}{ Disability Type } & \multicolumn{5}{|l|}{ Severity } \\
\cline { 2 - 6 } & $\mathbf{0}$ & $\mathbf{1}$ & $\mathbf{2}$ & $\mathbf{3}$ & $\mathbf{4}(+)$ \\
\hline $\begin{array}{l}\text { Vision } \\
\text { Disability }\end{array}$ & 0.98 & 0.72 & 0.47 & 0.20 & 0.26 \\
\hline $\begin{array}{l}\text { Hearing } \\
\text { Disability }\end{array}$ & 0.98 & 0.91 & 0.79 & 0.81 & 0.83 \\
\hline $\begin{array}{l}\text { Restricted } \\
\text { Mobility }\end{array}$ & 1.00 & 0.80 & 0.77 & 0.67 & 0.51 \\
\hline $\begin{array}{l}\text { Restricted } \\
\text { Co-ordination/ } \\
\text { Dexterity }\end{array}$ & 0.99 & 0.77 & 0.55 & 0.60 & 0.40 \\
\hline $\begin{array}{l}\text { Learning/ } \\
\text { Memory } \\
\text { Disability }\end{array}$ & 0.98 & 0.81 & 0.47 & 0.49 & 0.43 \\
\hline $\begin{array}{l}\text { Psychological/ } \\
\text { Psychiatric } \\
\text { Disability }\end{array}$ & 0.98 & 0.72 & 0.53 & $\mathrm{NA}^{2}$ & $\mathrm{NA}^{2}$ \\
\hline
\end{tabular}

As shown in Table 7, the likelihood of being in any type of employment decreases with increasing severity of disability. The impacts of disability are most marked at the highest levels of severity (levels 3 and 4 ) for those categories showing impact ratios 0.20 and 0.26 respectively. This finding reinforces the results of the
2001 Saskatchewan Employer Survey (Scott 2003) in which only $6 \%$ of employers said they had jobs that someone who was 'blind or visually impaired' could do, when presented with a list of nine disability types. This was the joint lowest rating of the nine types, and identified those with severe vision disabilities as the people employers would have the most difficulty accommodating in their workplace.

Conversely, for those with hearing disabilities, the impact ratios for severity levels 3 and 4 were 0.81 and 0.83 respectively. While these figures represent a reduction of employment of approximately a fifth of the expected level in the absence of disability, those with hearing disabilities are, nonetheless, less adversely affected than other groups.

\section{Joint Impact of Disability Type and Severity on Full-Time Employment}

When full-time employment outcomes are examined across disability subgroups, the impact of having a disability is a lot more pronounced, with very steep dropoffs particularly visible between the 0 and 1 categories in Figures 7 to 12 below. As elsewhere, the pattern observed for the hearing group is not so consistent as for other categories. This group is, nonetheless, considerably disadvantaged when full-time employment outcomes are examined.

The gap between the top of each bar and the line indicating the expected level of full-time employment in the absence of a disability widens as severity of disability increases. This gap analysis is summarised in the following section. 
Figure 7: Full-Time Employment Outcome for Those with Vision Disabilities

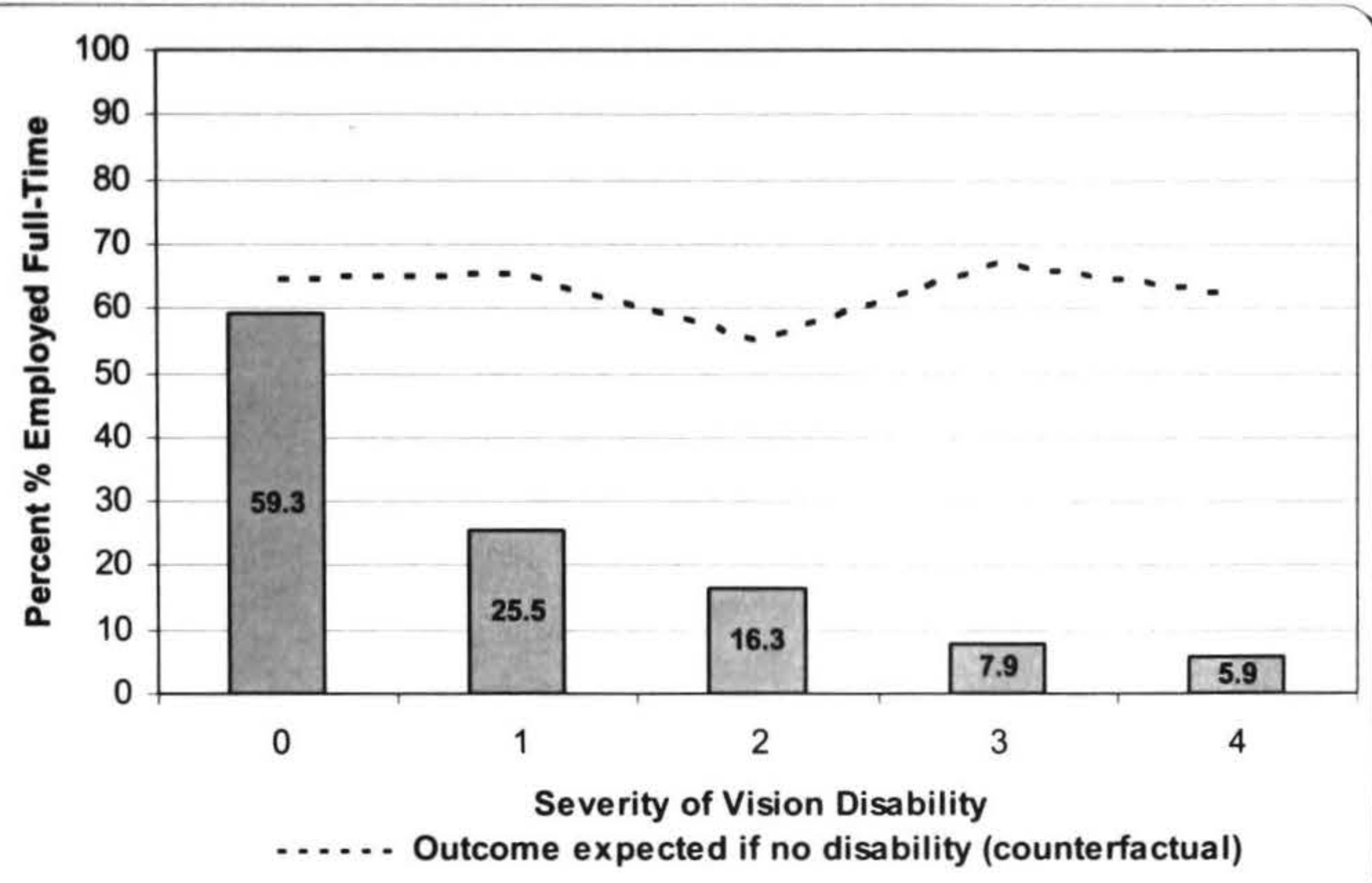

Figure 8: Full-Time Employment Outcome for Those with Restricted Mobility

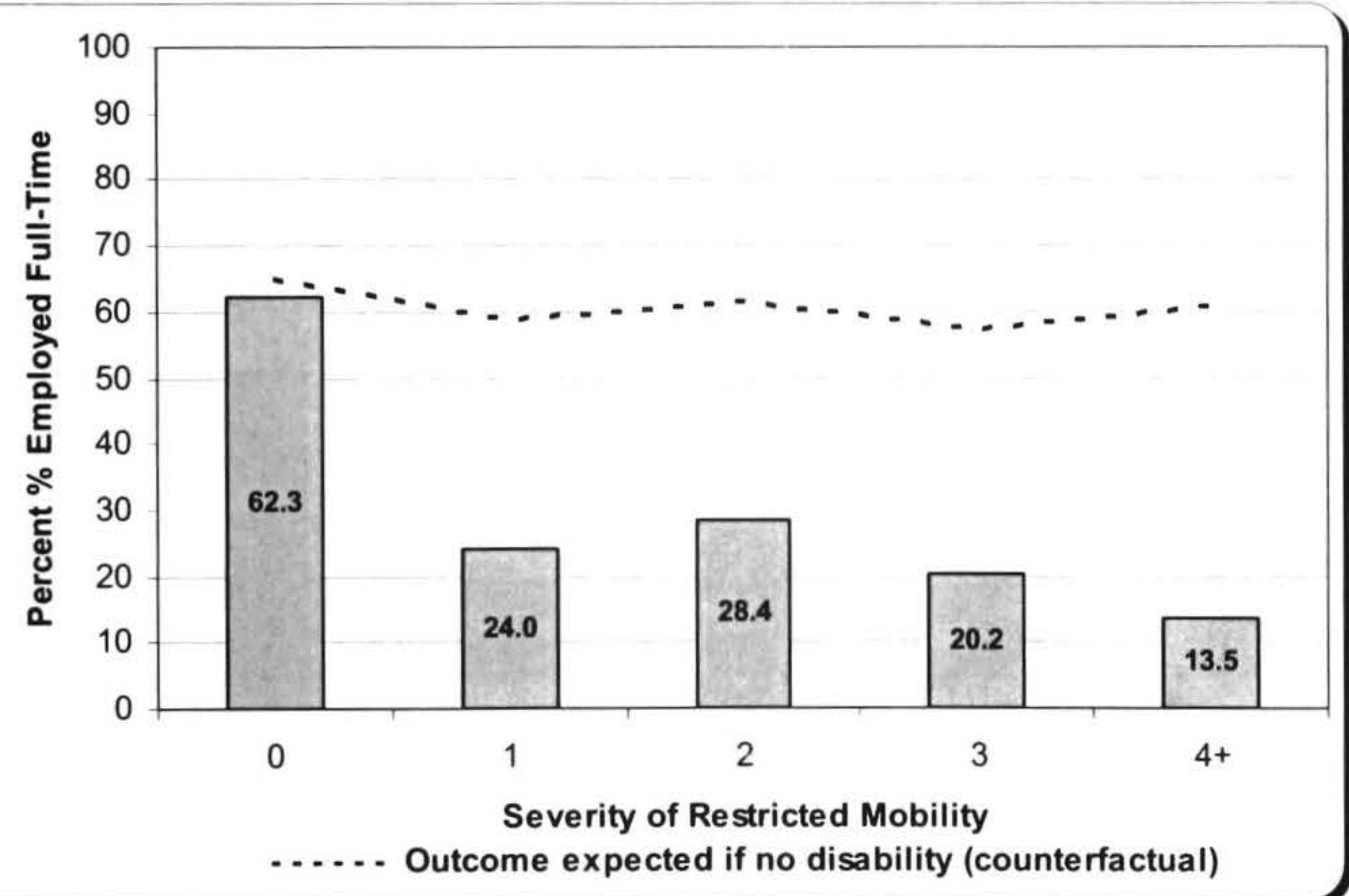


Figure 9: Full-Time Employment Outcome for Those with Restricted Co-ordination/Dexterity

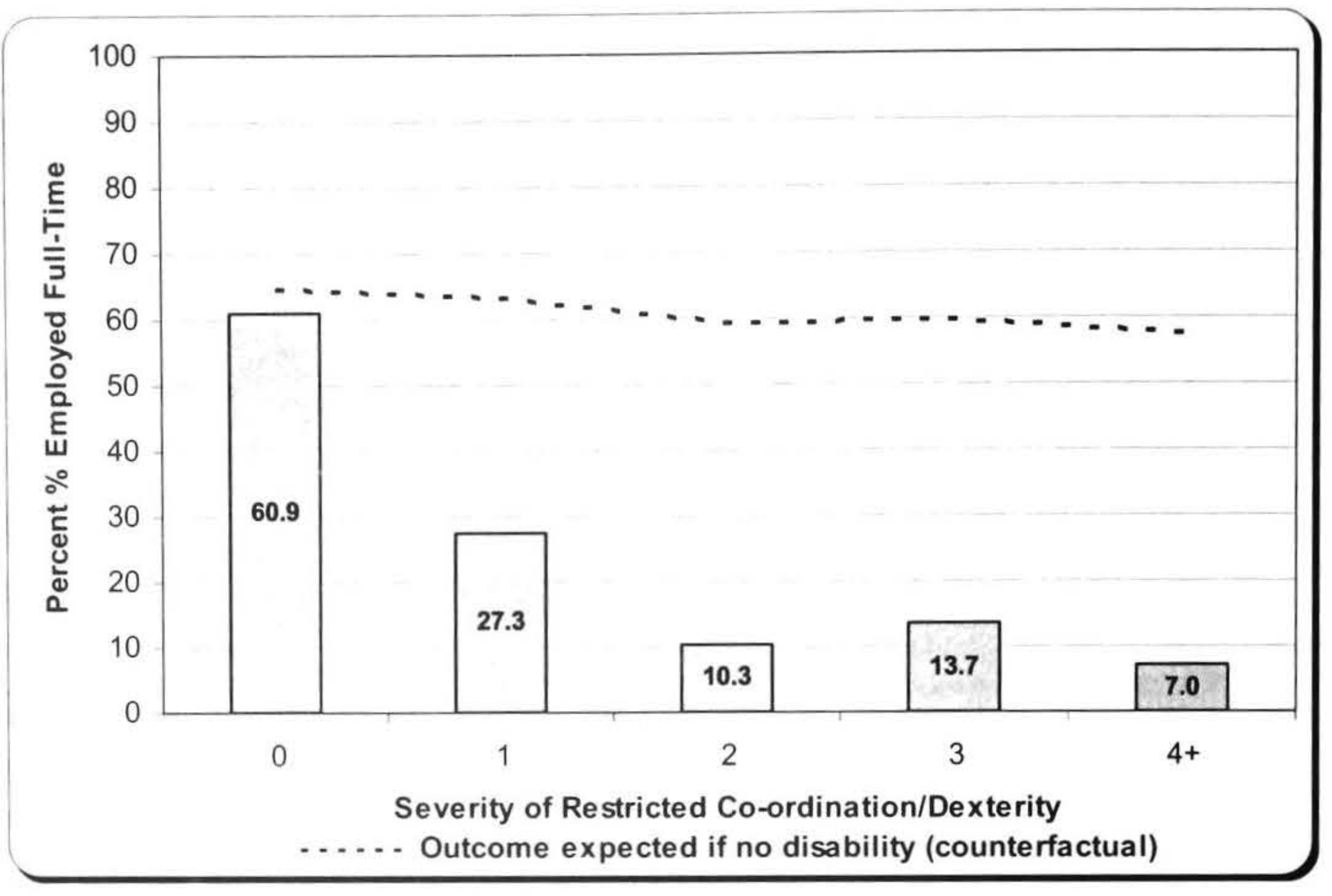

Figure 10: Full-Time Employment Outcome for Those with Hearing Disabilities

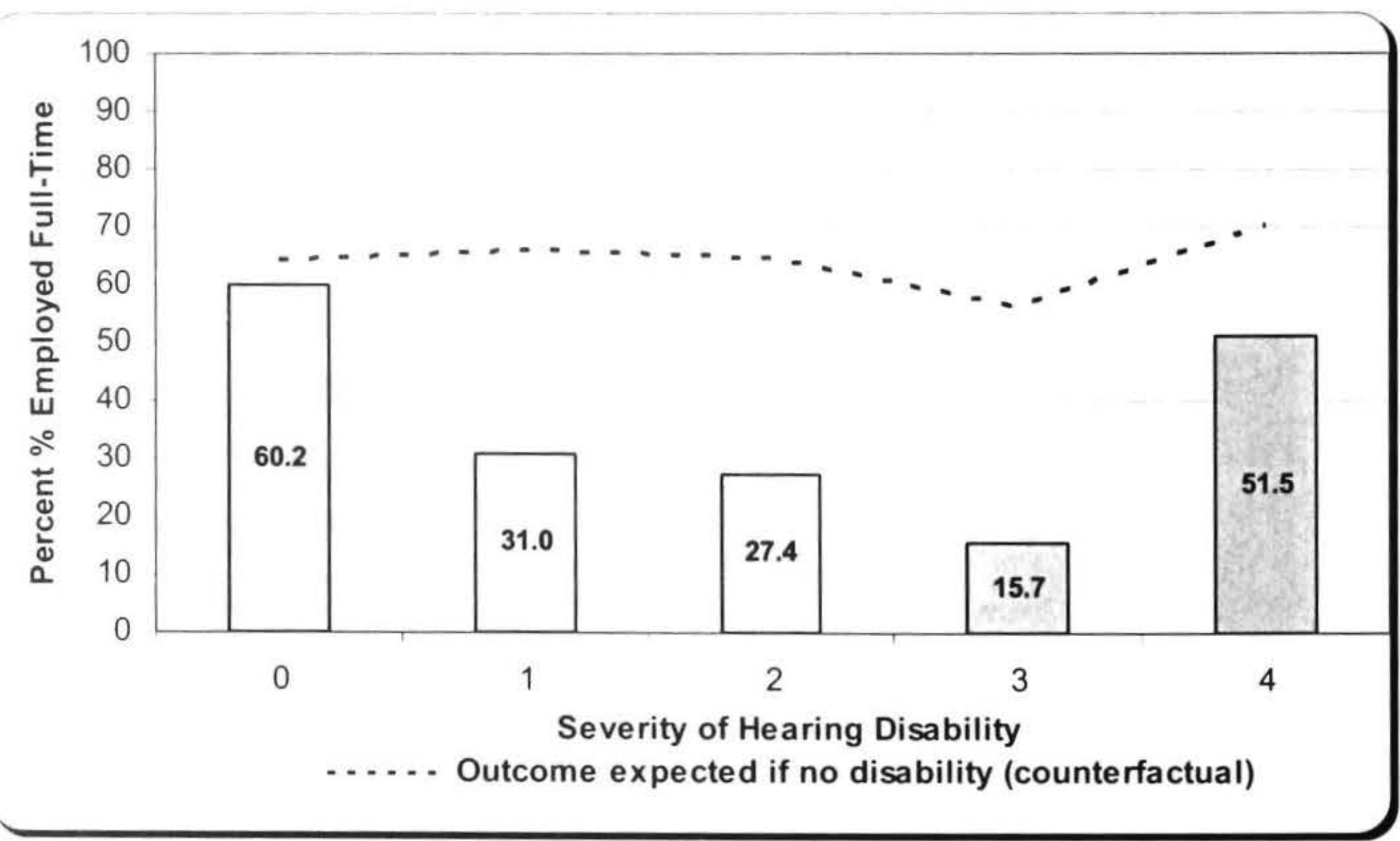


Figure 11: Full-Time Employment Outcome for Those with Learning/Memory Disabilities

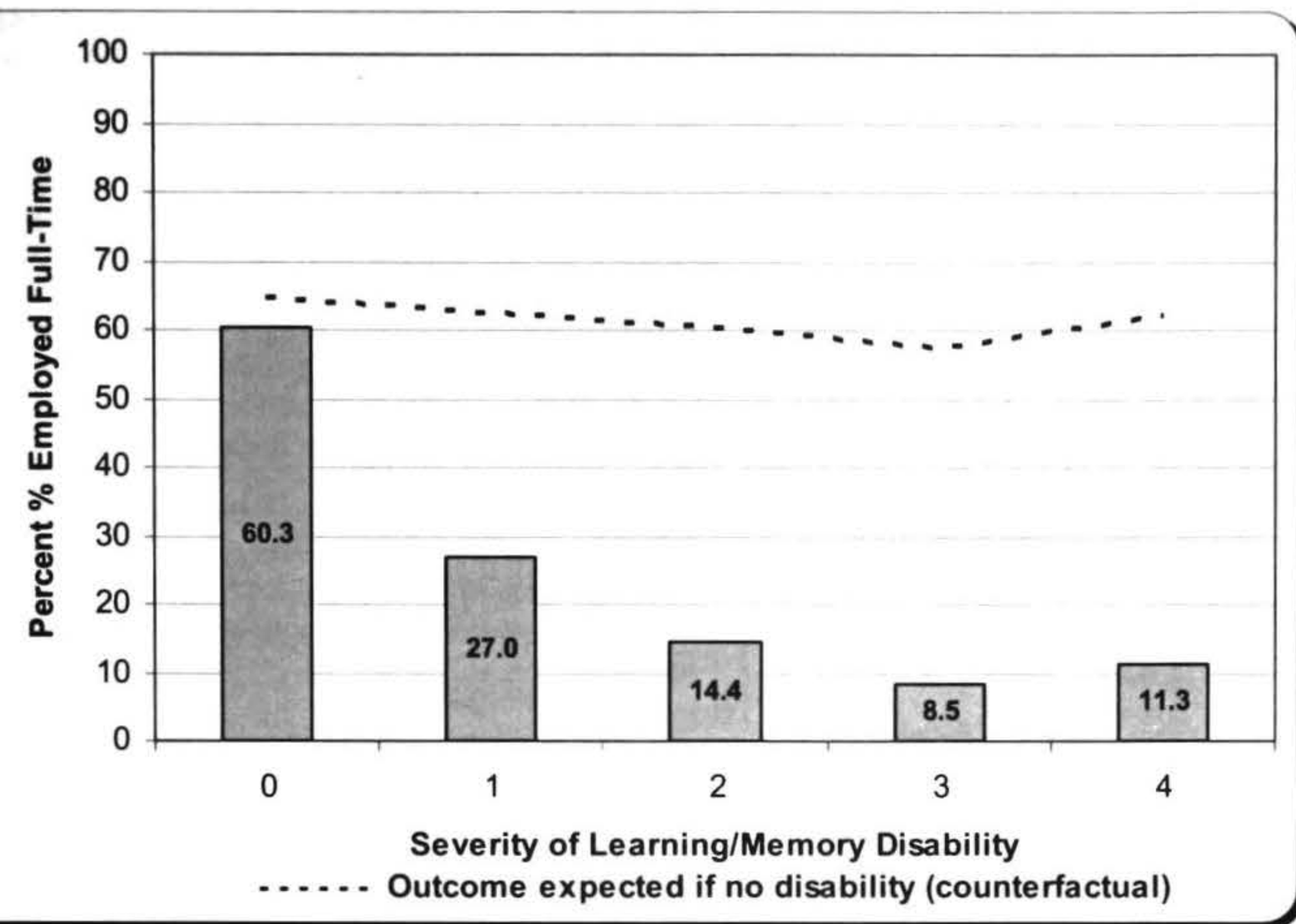

Figure 12: Full-Time Employment Outcome for Those with Psychological/Psychiatric Disabilities

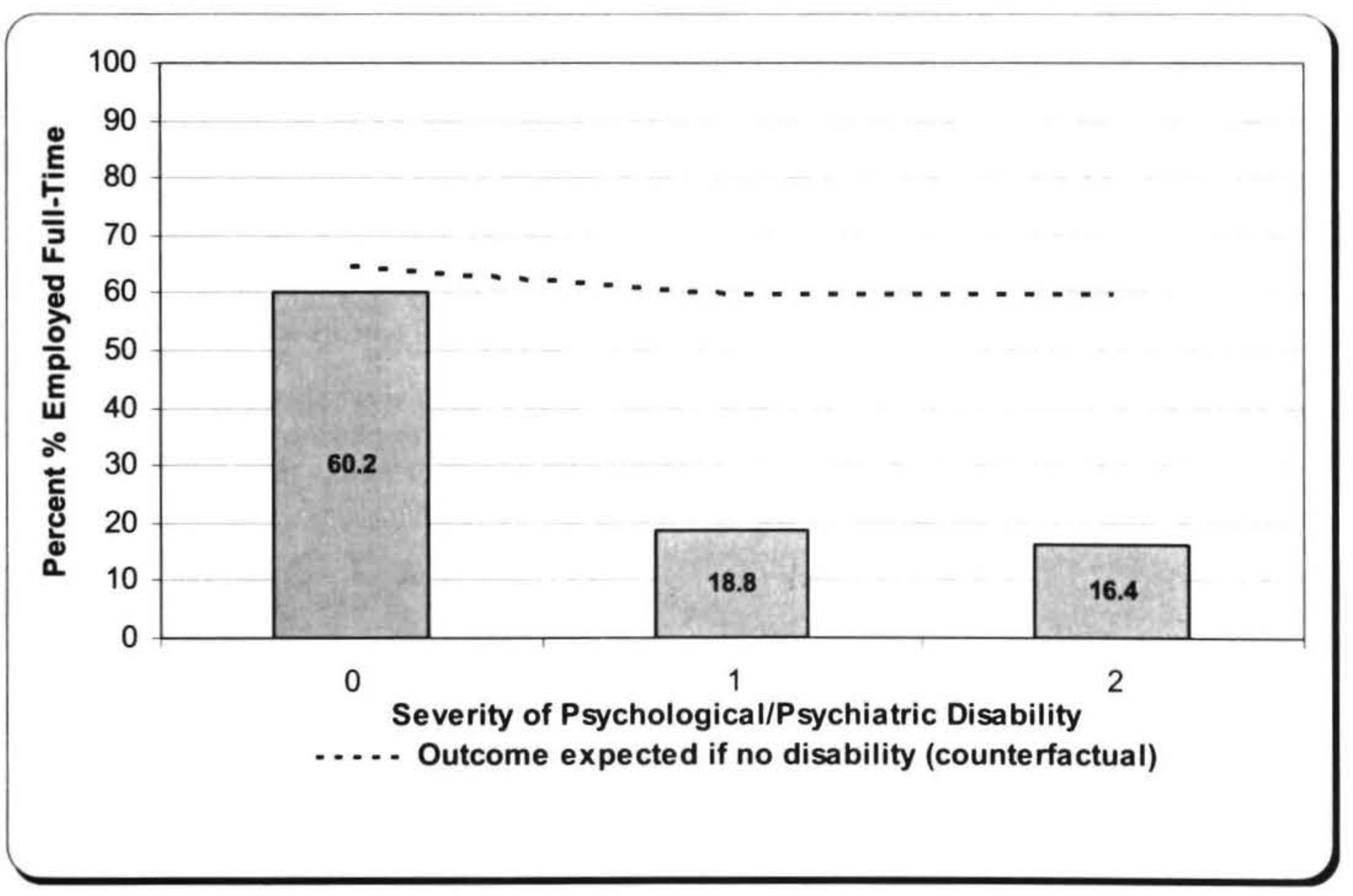




\section{Summary: Impact Analysis-Full-Time Employment}

The following table shows the ratio of the actual full-time employment outcomes to the counterfactual proportions for employment of people with various disabilities, at various levels of severity. This analysis is represented in Figures 7-12 above, and is summarised in Table 8.

Table 8: Joint Impact of Disability Type and Severity on Full-Time Employment for Those Aged 18-64 Years

\begin{tabular}{|c|c|c|c|c|c|}
\hline \multirow[t]{2}{*}{ Disability Type } & \multicolumn{5}{|c|}{ Severity } \\
\hline & 0 & 1 & 2 & 3 & $4(+)$ \\
\hline $\begin{array}{l}\text { Vision } \\
\text { Disability }\end{array}$ & 0.92 & 0.39 & 0.30 & 0.12 & 0.10 \\
\hline $\begin{array}{l}\text { Hearing } \\
\text { Disability }\end{array}$ & 0.93 & 0.47 & 0.42 & 0.28 & 0.73 \\
\hline $\begin{array}{l}\text { Restricted } \\
\text { Mobility }\end{array}$ & 0.96 & 0.41 & 0.46 & 0.35 & 0.22 \\
\hline $\begin{array}{l}\text { Restricted } \\
\text { Co-ordination/ } \\
\text { Dexterity }\end{array}$ & 0.94 & 0.43 & 0.17 & 0.23 & 0.12 \\
\hline $\begin{array}{l}\text { Learning/ } \\
\text { Memory } \\
\text { Disability }\end{array}$ & 0.93 & 0.43 & 0.24 & 0.15 & 0.18 \\
\hline $\begin{array}{l}\text { Psychological/ } \\
\text { Psychiatric } \\
\text { Disability }\end{array}$ & 0.93 & 0.32 & 0.27 & $\mathrm{NA}^{2}$ & $\mathrm{NA}^{2}$ \\
\hline
\end{tabular}

As was the case for any level of employment, those with vision disabilities are most adversely affected at the highest severity levels ( 3 and 4 ), for which the impact ratios were 0.12 and 0.10 respectively.

The relationship between full-time employment outcomes and severity of hearing disability does not show a clear gradient with respect to severity. It is notable that, at level 4 , all disability groups, barring hearing disability, have less than a quarter of the expected level of full-time employment in the absence of a disability.

\section{The Disability-Related Exclusion Risk Score Indicator (DERS)}

This section looks at how employment outcomes vary when the number, type and severity of disabilities are all considered together.
To do this, an examination was made of the extent to which severity scores on the six types of disability, taken together, could account for statistical variation in employment participation, and whether it would be possible to devise a comparatively simple but efficient procedure for producing a risk score that would be predictive of non-participation. The analysis demonstrated that the latter was feasible, and resulted in the specification of a score that has been called the Disability-Related Exclusion Risk Score (DERS). To calculate an individual's DERS score, the non-truncated severity scores are subjected to simple transformations that produce new integer values that make approximately equal contributions to estimating non-employment risk, and thus are able to be simply added together without loss of efficiency. The effect of the transformations it to provide a simple weighting of the severity scores ${ }^{3}$.

A DERS score of zero indicates that the person does not have a disability of any of the six types. On the following graphs, a score of zero is labelled ND, for "no disability". People with scores of 9 or more have been amalgamated together.

The term 'risk' is used here in a statistical sense, relating to probability. Use of this term is not meant to imply that employment is always appropriate for every person with a disability. The approach (although not the specific estimation procedures) is similar to that employed by Berthoud (2003a) who also used a cumulative risk model and found that the higher the number of disabilities experienced and the greater the severity, the higher the risk of non-employment.

\section{Additive Risk: The Overall Impact of Disability and Severity on Labour Market Outcomes}

When DERS scores are graphed against employment outcomes (any employment and full-time employment), sharp reductions in employment are observed as the risk score increases. The rate of full-time employment shows a greater reduction across the DERS range than does the rate of any employment. The same pattern was seen earlier for each disability type in the results showing employment rates graphed severity scores.

The graph for any employment shows that those with a DERS value of 5 had an employment rate of about $35 \%$, while those with a score of 9 had a rate of $11 \%$ (less than a third of the former value). 


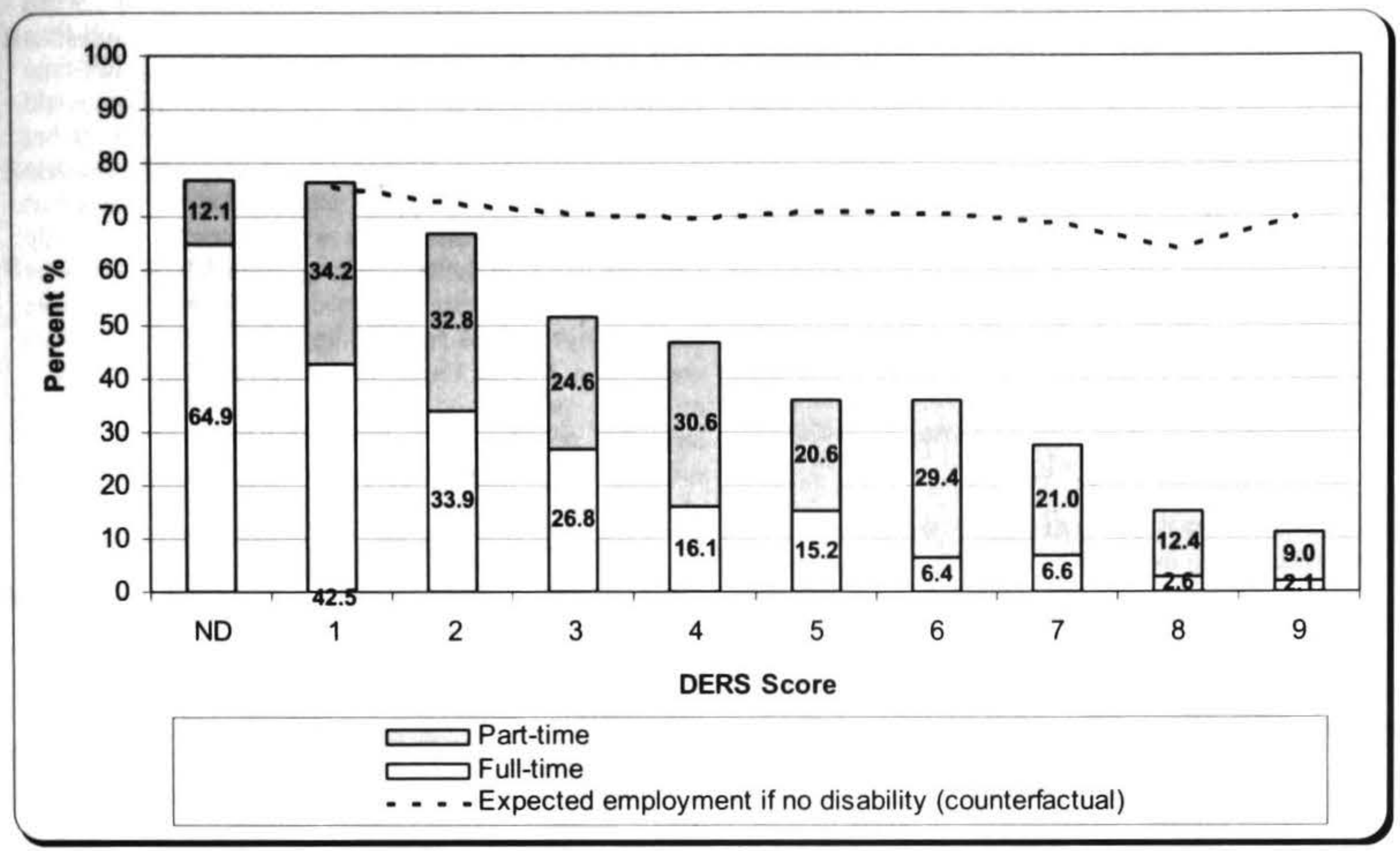

The graph below shows that those with a DERS value of 5 had a full-time employment rate of $15 \%$, while those with a score of 9 had a rate of only $2 \%$.

Figure 14: Disability-Related Exclusion Risk Score (DERS) and Full-Time Employment Levels

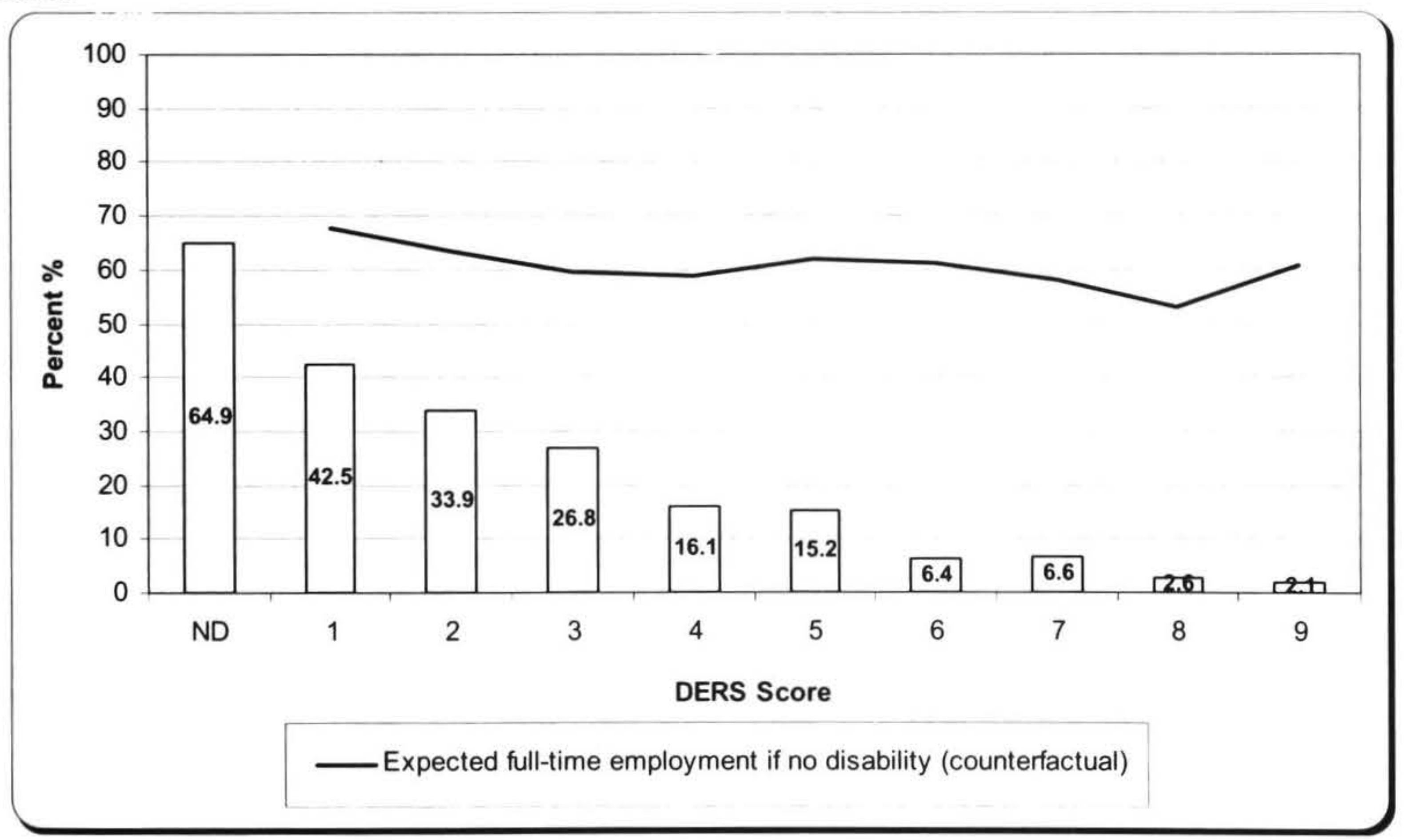

Table 9: Impact of DERS on Labour Market Outcomes for Those Aged 18-64 Years

\begin{tabular}{|l|c|c|c|c|c|c|c|c|c|c|}
\hline \multirow{2}{*}{ Type of Outcome } & \multicolumn{10}{|c|}{ DERS Score } \\
\cline { 2 - 22 } & ND & $\mathbf{1}$ & $\mathbf{2}$ & $\mathbf{3}$ & $\mathbf{4}$ & $\mathbf{5}$ & $\mathbf{6}$ & $\mathbf{7}$ & $\mathbf{8}$ & $\mathbf{9}$ \\
\hline Any Employment & 1.00 & 1.01 & 0.92 & 0.73 & 0.67 & 0.50 & 0.51 & 0.40 & 0.23 & 0.16 \\
\hline Full-Time Employment & 1.00 & 0.63 & 0.54 & 0.45 & 0.27 & 0.24 & 0.10 & 0.11 & 0.05 & 0.04 \\
\hline
\end{tabular}


The strong relationship between the DERS score and employment levels confirms the validity of an approach that combines both number and severity of limitations. It might be argued that a person who has three activities they can do with difficulty is less severely disabled than a person who has one activity they cannot perform at all, although the former would have a higher DERS score. However, Figure 21 shows that DERS works well as an indicator of likelihood of employment.

As was the case with disability subcategories, when fulltime employment outcomes and expectations are concerned, impacts are accentuated, as shown in Figure 22 above. With increasing DERS scores, full-time employment decreases, with a rate of less than $10 \%$ for scores of 6 and above.

Table 9 above shows the ratio of the actual labour market outcomes attained to the counterfactual expectation levels for people at various levels of risk, as captured by the DERS indicator. The results of this analysis are shown in Figures 13-14 above, and are summarised in Table 9.

\section{Conclusion}

As discussed in the introduction to this paper, most developed countries have had increases over recent years in the numbers of people receiving income support benefits for ill health and disability. In many such countries, the latter groups now constitute the majority of income support beneficiaries, with disability benefits costing more than unemployment benefits in 19 out of 20 OECD countries for which comparable statistics are currently available (OECD 2003).

In New Zealand, the number of people receiving a Sickness Benefit (SB) has increased from approximately 29,000 in June 1993 to 40,000 in June 2003, while the number receiving an Invalids Benefit (IB) has almost doubled over this same period, from approximately 35,000 to 69,000 . In addition, at 3 April 2004, there were 15,583 claimants aged 16-64 years in receipt of ACC weekly compensation of 26 weeks or more duration. These developments provide the background to the present research and part of the impetus to carry it out. The research is aimed at understanding variation in employment amongst the disability population and the contribution that disability has made to these outcomes.

Disabilities have been grouped into six broad types, using an empirically derived typology produced for the purposes of this study. The results of the impact analysis show that each of the six types of disability has a negative impact on employment but that the effect is smaller for a hearing disability than for any of the other five types of disability. Furthermore, for a hearing disability, the effect on total employment does not seem to vary with regard to the severity of the disability. For all other disability types, increased severity results in a reduced rate of employment. An interesting question arises concerning why a hearing disability might have less adverse consequences for employment than another type of disability.
One of the most striking features of the results is that the impact of disability is relatively modest when employment is measured as part-time or full-time employment, but is large in relation to full-time employment. Although some types of disability would permit a person to engage in a small amount of work but preclude full-time work, many types of disability would not cause this restriction. This suggests the possibility that many people with disabilities who currently work only part time have the potential to engage in full-time work if better employment support mechanisms were available and employers were more willing to employ them. This could be a fruitful focus for future research on how it might be possible to raise the level of employment amongst people with disabilities. Areas of future investigation could include factors such as how to support people with disabilities into all types of employment including self-employment, the nature of the support required to facilitate increased employment, how to overcome 'demand side' barriers to employment faced by those with disabilities and what mechanisms are required to facilitate sustainable employment for those with disabilities.

The Ministry of Social Development has embarked on a strategy for assisting people with ill health and disability. This is in response to the growth in the numbers of people receiving $\mathrm{SB}$ or $\mathrm{IB}$, in recognition of the need to improve planning for an ageing population and the need to widen New Zealand's employment base to include groups that have traditionally been disregarded in employment policy. The Ministry's strategy focuses on illuminating the barriers to social and economic participation caused by disabilities, and to creating greater inclusion in society through the removal of those barriers.

This report adds to current understanding of the extent to which disability limits participation in society and provides an improved evidential basis for policy analysis currently being undertaken to develop new ways of reducing the barriers faced by people with disabilities. Ultimately, though, more understanding is required of the ways in which disability creates barriers and limits the lives of those affected. The findings of the report point to some areas where new research can usefully be directed. Such research could yield substantial returns. Policy innovation based on a strengthened knowledge base has the potential to raise the level of participation in employment and also other areas, to the benefit not only of people with disabilities but also of society as a whole.

\section{Notes}

1. This information was made available to the Ministry of Social Development (MSD) as part of the ACCMSD joint research programme.

2. Because of the small number of items available (2) to produce the psychological/psychiatric disability score, it is possible to distinguish only three score values of $(0,1,2)$, with no values of 3 or 4 ; cf Section 4 of this report.

3. The hearing disability severity score does not contribute to the DERS score. This is because employment outcomes do not have a clear gradient on the hearing score. 


\section{References}

Berthoud, R. (2003a). Multiple disadvantage in employment: A quantitative analysis. York, UK: Joseph Rowntree Foundation.

Berthoud, R. (2003b). Disabled people and jobs. Benefits, 38, 169-174.

Burchardt, T. (2003). Being and Becoming: Social exclusion and the onset of disability. London: Centre for Analysis of Social Exclusion, London School of Economics.

Health Funding Authority / Ministry of Health. (1998). Disability in New Zealand: Overview of the 1996/97 Surveys. Wellington: Health Funding Authority / Ministry of Health.

Hogelund, J. and Pedersen, J.G. (2001). The Employment Situation of the Disabled People in Denmark. Denmark: The Danish National Institute of Social Research.

Human Rights Commission. (2004). Human Rights in New Zealand Today Ngā Tika Tangata o te Motu. Wellington: Human Rights Commission.

International Social Security Association (ISSA). (2002). Who Returns to Work and Why? A Summary. Geneva, Switzerland: ISSA.

Jensen, J., Sathiyandra, S., Rochford, M., Jones, D., Krishnan, V. and McLeod, K. (2004). Disbability and Work Participation in New Zealand. Wellington: Ministry of Social Development.
Ministry of Social Development. (2003). Statement of Intent 2003. Wellington: Ministry of Social Development.

OECD (Organisation for Economic Co-operation and Development). (2000). Finland July 2000: OECD Country Report. Paris, France: Organisation for Economic Co-operation and Development.

OECD (Organisation for Economic Co-operation and Development). (2003). Transforming Disability into Ability. Paris, France: OECD.

Scott, D. (2003). Disability and Labour Market Attachment: Assessing and Responding to the Needs of the Saskatchewan Social Assistance Clients. Regina, Canada: Saskatchewan Community Resources and Employment.

Statistics New Zealand: www.stats.govt.nz

Taylor, J.B. and Dalziel, P. (2002). Macroeconomics: New Zealand edition. Australia: John Wiley \& Sons.

Wilkins, R. (2003). Labour Market Outcomes and Welfare Dependence of Persons with Disabilities in Australia. Melbourne: Melbourne Institute of Applied Economic and Social Research, University of Melbourne.

Yelin, E.H. and Trupin, L. (2003). Disability and characteristics of employment. Monthly Labour Review, May 2003, 20-31. 